University of Montana

ScholarWorks at University of Montana

Numerical Terradynamic Simulation Group

Publications

Numerical Terradynamic Simulation Group

2013

\title{
The relationship of large fire occurrence with drought and fire danger indices in the western USA, 1984-2008: the role of temporal scale
}

\author{
Karin Lynn Riley \\ The University of Montana \\ John Abatzoglou \\ University of Idaho, Moscow \\ Isaac C. Grenfell \\ The University of Montana \\ Anna E. Klene \\ University of Montana - Missoula \\ Faith Ann Heinsch
}

Follow this and additional works at: https://scholarworks.umt.edu/ntsg_pubs

Let us know how access to this document benefits you.

\section{Recommended Citation}

Riley, Karin L.; Abatzoglou, John T.; Grenfell, Isaac C.; Klene, Anna E.; Heinsch, Faith Ann. 2013. The relationship of large fire occurrence with drought and fire danger indices in the western USA, 1984-2008:

The role of temporal scale. International Journal of Wildland Fire. 22: 894-909. doi: http://dx.doi.org/ 10.1071AVF12149

This Article is brought to you for free and open access by the Numerical Terradynamic Simulation Group at ScholarWorks at University of Montana. It has been accepted for inclusion in Numerical Terradynamic Simulation Group Publications by an authorized administrator of ScholarWorks at University of Montana. For more information, please contact scholarworks@mso.umt.edu. 


\title{
The relationship of large fire occurrence with drought and fire danger indices in the western USA, 1984-2008: the role of temporal scale
}

\author{
Karin L. Riley ${ }^{\mathrm{A}, \mathrm{E}}$, John T. Abatzoglou ${ }^{\mathrm{B}}$, Isaac C. Grenfell ${ }^{\mathrm{C}}$, Anna E. Klene ${ }^{\mathrm{D}}$ \\ and Faith Ann Heinsch ${ }^{\mathrm{C}}$ \\ A University of Montana, Department of Geosciences, Missoula, MT 59812, USA. \\ ${ }^{B}$ University of Idaho, Department of Geography, Moscow, ID 83844, USA. \\ CUSDA Forest Service, Rocky Mountain Research Station, Fire Sciences Laboratory, \\ 5775 W US Highway 10, Missoula, MT 59808, USA. \\ DUniversity of Montana, Department of Geography, Missoula, MT 59812, USA. \\ ${ }^{\mathrm{E}}$ Corresponding author. Email: kriley@fs.fed.us
}

\begin{abstract}
The relationship between large fire occurrence and drought has important implications for fire prediction under current and future climates. This study's primary objective was to evaluate correlations between drought and firedanger-rating indices representing short- and long-term drought, to determine which had the strongest relationships with large fire occurrence at the scale of the western United States during the years 1984-2008. We combined 4-8-km gridded drought and fire-danger-rating indices with information on fires greater than 404.7 ha (1000 acres). To account for differences in indices across climate and vegetation assemblages, indices were converted to percentile conditions for each pixel. Correlations between area burned and short-term indices Energy Release Component and monthly precipitation percentile were strong $\left(R^{2}=0.92\right.$ and 0.89$)$, as were correlations between number of fires and these indices $\left(R^{2}=0.94\right.$ and $0.93)$. As the period of time tabulated by indices lengthened, correlations with fire occurrence weakened: Palmer Drought Severity Index and 24-month Standardised Precipitation Index percentile showed weak correlations with area burned $\left(R^{2}=0.25\right.$ and -0.01$)$ and number of large fires $\left(R^{2}=0.3\right.$ and 0.01$)$. These results indicate associations between shortterm indices and moisture content of dead fuels, the primary carriers of surface fire.
\end{abstract}

Additional keywords: area burned, ERC, MTBS, number of fires, PDSI, precipitation, SPI.

Received 17 December 2012, accepted 7 March 2013, published online 23 July 2013

\section{Introduction}

Wildland fire risk to highly valued resources influences land management planning, budgeting for firefighting and fuels reduction work, and positioning of suppression resources in the United States (Ager et al. 2010; Calkin et al. 2011; Finney et al. $2011 \mathrm{~b}$ ). Current modelling efforts have produced burn probability maps for the continental US that are statistically similar to recent fire activity (Finney et al. 2011b), and statistical models that incorporate climate data have exhibited better-than-random prediction of area burned (Westerling et al. 2002; Preisler and Westerling 2007; Preisler et al. 2009), but several challenges in fire prediction remain. Large fires occur stochastically, in response to lightning produced by localised convective storms and human ignitions, making prediction of the location and timing of fires difficult. As the climate changes, temperature and precipitation regimes fluctuate, which may affect the occurrence of large fires. Given these uncertainties, it is important to understand the mechanisms by which various drought and fire danger indices (which capture different timescales of drought) are empirically related to large fire occurrence, and the strength of these relationships.

Another challenge in studies of wildland fire and climate is that large fires are rare events. Accordingly, much previous work on fire and climate has taken place at large spatial scales at annual timesteps, or over timeframes of multiple centuries, in order to encompass a large enough sample size of fires for statistical analysis to be possible. In the case of fire history work, most studies take place over several hundred years at an annual timestep that chronicles both drought (inferred from tree ring width) and fire occurrence (based on positioning of fire scars relative to tree rings) (e.g. Baisan and Swetnam 1990; Swetnam and Betancourt 1998; Hessl et al. 2004; Heyerdahl et al. 2008b; Morgan et al. 2008). Previous studies have linked some of the variability in fire occurrence and area burned with synoptic weather patterns such as persistent high pressure blocking ridges and coupled atmosphere-ocean teleconnections (e.g. El NiñoSouthern Oscillation) that correlate with droughts (Gedalof et al. 2005; Abatzoglou and Kolden 2011). Owing to limitations in 
fire reporting before 1970 , when statistics were aggregated annually by National Forest or state, studies associating fire and climate often utilised annual timesteps (Gedalof et al. 2005, Karen Short, pers. comm.). However, daily and monthly fluctuations in weather are strong determinants of fire ignition and spread. Recently, finer-scale weather data and a comprehensive database of large fires have become available, enabling analysis of the relationship between drought and fire at a more detailed spatial and temporal scale. An improved understanding of the time-scales and means through which climate and weather influence fire occurrence would be beneficial to fire prediction efforts as well as operational fire management, and provide a way for researchers to link predictions of climate change with their potential effect on future fire occurrence.

Precipitation is related to fire occurrence via several mechanisms. (1) In dead fuels such as litter and downed woody debris, fuel moisture is controlled by environmental conditions including precipitation, relative humidity, solar radiation and temperature. In the absence of precipitation, dead vegetation (fuels) will dry out, converging towards ambient relative humidity over a period of days or weeks, the period increasing with fuel diameter (Fosberg 1971). (2) During prolonged dry periods (which occur seasonally in some areas), live herbaceous and woody shrub vegetation may enter dormancy or die, contributing to the loading of fine dead surface fuels $(<0.635 \mathrm{~cm}$ $\left(<0.25^{\prime \prime}\right)$ in diameter), which are the primary carriers of surface fire (Scott and Burgan 2005). (3) Live fuels decrease in moisture content during dry periods, and the proportion of flammable compounds may increase (Matt Jolly, pers. comm.). (4) Ignition and propagation of fire is more likely when fuels are dry, and fire rates of spread are higher (Rothermel 1972; Andrews et al. 2003; Scott and Burgan 2005).

Live and dead fuel moistures thus fluctuate across a range of timescales, from daily (due to rain events), to seasonally (in much of the western US, new live vegetation typically grows during spring and cure during dry summers), to decadally (in response to extended droughts). Various fire danger and drought metrics utilise different temporal scales that are implicitly related to these fuel moisture dynamics, but more work is needed to relate these metrics to fire occurrence in the western US, both empirically and physically. Use of indices based on fuel moisture values derived from recent weather could strengthen fire modelling efforts, because some frequently used metrics may not be directly related to fire ignition and behaviour.

We quantified the correlation of eight drought and fire danger metrics with large ( $>404.7$ ha or 1000 acres) fire occurrence, defined using two criteria: area burned and number of fires. The drought and fire danger indices included in this study were: Standardised Precipitation Index (SPI) calculated for 3-, 6-, 9-, 12- and 24-month intervals, Palmer Drought Severity Index (PDSI), monthly precipitation totals (PPT) and Energy Release Component (ERC). These indices were selected based on their common usage in the literature regarding drought and fire in the western US, or our assessment of their potential for capturing the relationship between drought and fire occurrence. The goals of this study were to: (1) examine which, if any, of these metrics were strongly related to fire occurrence across the western US, independent of ecoregion, climatic zone and vegetation type, and (2) investigate whether the timescale of the indices affected the strength of their correlations with fire occurrence. A metric that is strongly correlated with fire occurrence across this region could be utilised with high confidence in fire prediction work at this scale. In addition, examining which metrics are strongly correlated with fire occurrence suggests physical mechanisms linking drought and fire.

\section{Methods}

\section{Study area}

The western US was chosen for this study because it spans several diverse fire-adapted ecoregions. In order to delineate the study area (Fig. 1) from the grasslands of the Great Plains, we used Omernik ecoregions (Omernik 1987).

\section{Data sources: addressing challenges in reporting \\ Fire records}

Fire records were obtained from the Monitoring Trends in Burn Severity (MTBS) project, conducted jointly by the US Forest Service and US Geological Survey, which maps the extent of large fires since 1984 based on Landsat imagery (Eidenshink et al. 2007). We limited fires included in this study

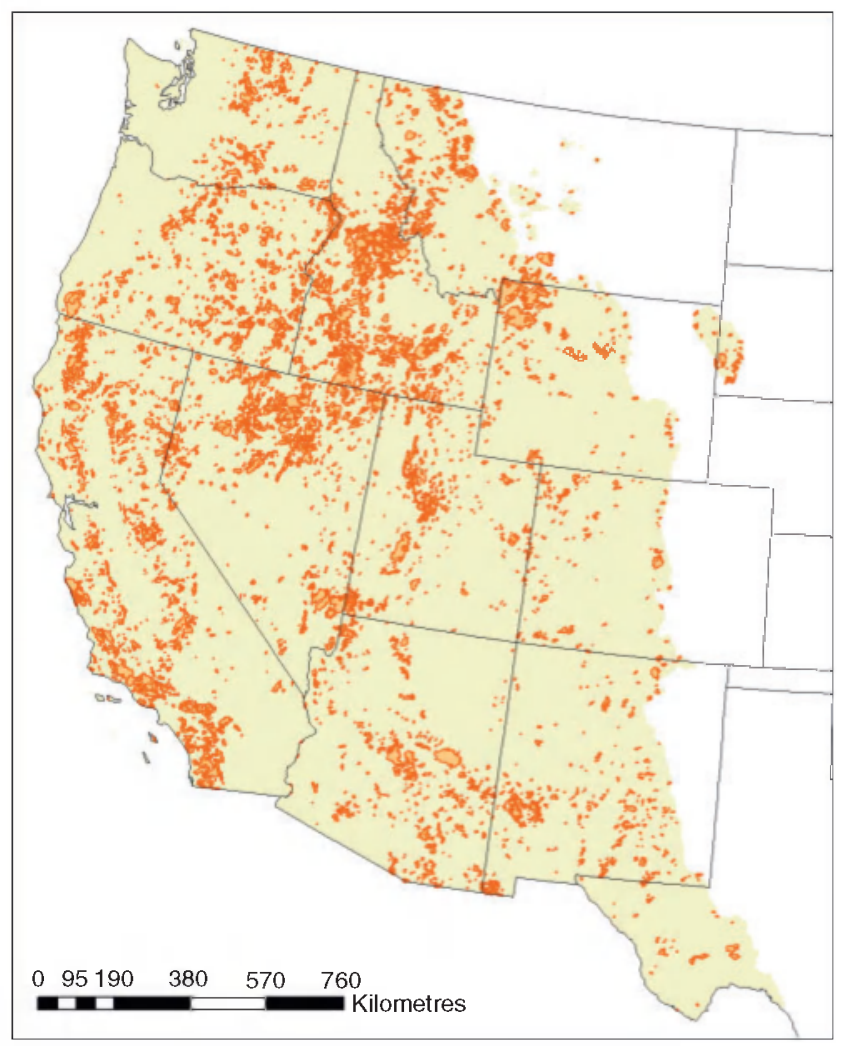

Fig. 1. Map of the study area in the western US, west of the grasslands of the Great Plains region, as delineated by Omernik ecoregion boundaries. This figure shows all fires included in the analysis, selected from the Monitoring Trends in Burn Severity database based on the following criteria: (1) fires with centroid inside the study area and (2) fires with burn area greater than or equal to 404.7 ha $(1000$ acres) in size. (Map projection: Albers.) 
$(n=5976)$ to those that had centroids within our study area boundary with start dates between 1 January 1984 and 31 December 2008. Only fires larger than 404.7 ha (1000 acres) were included, because large fires burn most of the area in this region (Strauss et al. 1989). Data on fire perimeters, areas, locations and discovery dates were provided by the MTBS project.

The MTBS project dataset addresses some issues that previously existed in fire records owing to inconsistent and incomplete reporting of wildland fires (Brown et al. 2002; Schmidt et al. 2002). No single comprehensive database tracks all fires in the US, so a complete record of fires must be compiled from records of multiple federal agencies (US Department of Agriculture Forest Service uses one system, a second system is employed by the US Department of Interior (USDOI) Fish and Wildlife Service, and a third system is used by USDOI's Bureau of Land Management, Bureau of Indian Affairs and National Park Service) as well as non-federal records (state databases, National Association of State Foresters records and the US Fire Administration's National Fire Incident Reporting System). Compiled records are subject to several issues, including incongruent reporting standards. For example, more than half of nonfederal fire records lack information on date, location or size, meaning that they cannot be used for analyses with spatial or temporal questions (Karen Short, pers. comm.). The MTBS project has determined the spatial locations and discovery dates of all fires in its dataset through geolocated burn scars, an advantage of this dataset. A second issue in compilations is duplicate records that can cause overestimates of area burned on the order of $40 \%$ (Karen Short, pers. comm.). Duplicate records occur most frequently where large fires cross land ownership boundaries, causing records to appear in multiple land agency reporting systems. Because the MTBS project dataset is based on changes in spectral signatures in Landsat imagery, duplicate records are eliminated and some previously unreported fires are detected. Compilations of fire records may also suffer from omissions, especially of smaller fires, which can cause underestimates of fire numbers. Because we limited our analysis to fires larger than 404.7 ha (1000 acres) in the western United States, this problem is minimised, but inference is limited to large fire events.

The intention of the MTBS project is to track wildland fires, but some prescribed fires have been included in the database through detection of changes in spectral signatures. At the time of this study, the MTBS project did not state whether each fire was prescribed or wildland, so we were unable to separate them. Data on daily fire progression is lacking or not readily available from the MTBS project or other sources, meaning the contribution of daily winds (an important factor in fire growth) could not be quantified for this study.

\section{Drought and fire danger indices}

The eight drought and fire danger indices analysed in this study provide a means for assessing relative wetness or dryness of the fire environment, and may serve as predictors of water availability, vegetation health and fire danger. We utilised spatially and temporally complete high-resolution gridded climate and meteorological datasets (Fig. 2). Monthly climate data from Parameter-elevation Regressions on Independent Slopes Model (PRISM; Daly et al. 1994a) at 4-km horizontal resolution were used to derive the PPT, PDSI and SPI indices

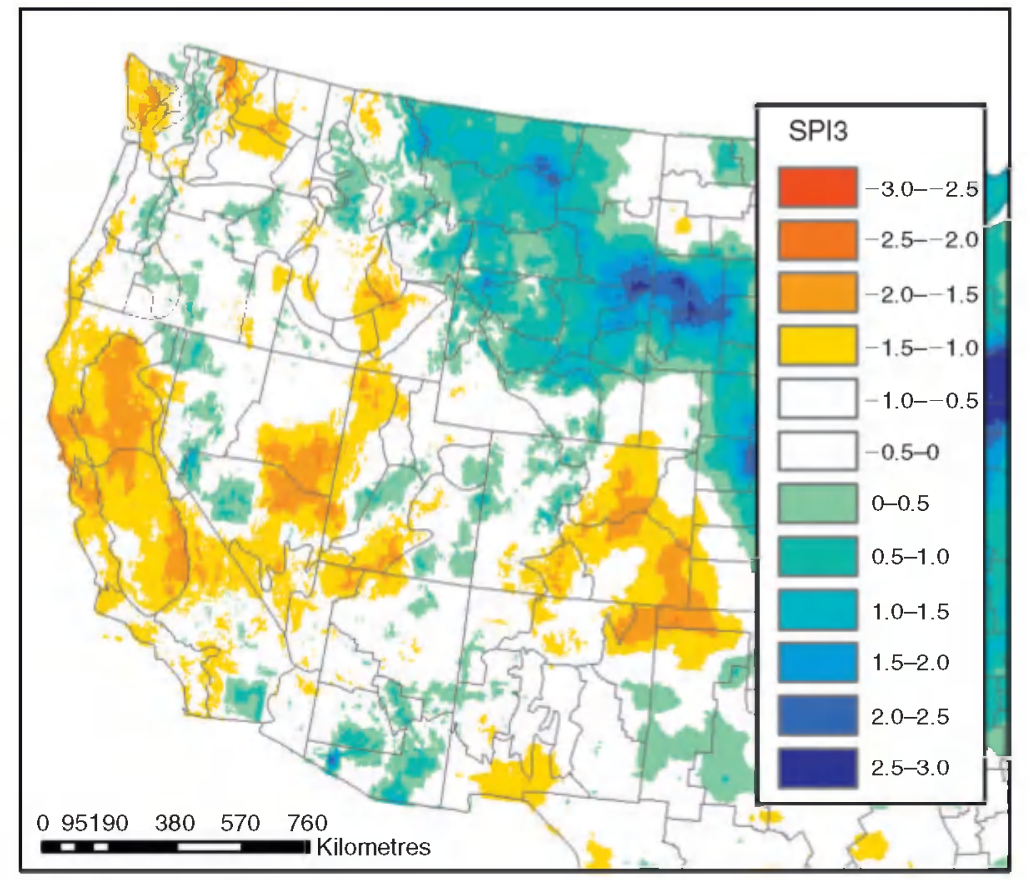

Fig. 2. Map of the western US with gridded 3-month Standardised Precipitation Index (SPI3) data for June 2008 and US Climate Division boundaries. The map illustrates the finescale variability in SPI3. (Map projection: Albers.) 
following Kangas and Brown (2007). The drought indices were calibrated to the 1895-2009 period of record, making them more robust than monthly drought indices calculated over shorter time periods. A complementary dataset developed by Abatzoglou (2013) provided a spatially and temporally complete daily meteorological dataset from 1979-2010, upsampled to 8-km resolution by employing high-frequency meteorological conditions from the North American Land Data Assimilation System (NLDAS) that is then bias-corrected using PRISM. The resultant dataset provided daily maximum and minimum temperatures, relative humidity, daily precipitation amount and duration, temperature, and state-of-the-weather code for 1300 hours (local time), all components necessary for calculations of ERC. This study utilised the products of these efforts: PPT, PDSI and SPI at 3-, 6-, 9-, 12- and 24-month timescales at a 4-km scale and monthly timestep, and $\mathrm{ERC}(\mathrm{G})$ at an 8 -km scale on a daily timestep.

Previous work on fire and climate faced challenges in obtaining consistent and complete weather records; these gridded datasets address some of these challenges. For example, Remote Automated Weather Stations (RAWS) used for fire danger calculations are subject to quality control problems and are often switched off when fire season ends, meaning that weather records are temporally incomplete. Until recently, weather data has typically been available only at sparse point locations with weather stations or summarised at coarse resolution. Researchers were presented with the choice of using weather data from a single station as a proxy for a large area, or using a dataset such as the National Climatic Data Center climate division data, which averages conditions from weather stations over large areas that do not necessarily correspond to ecoregion boundaries (e.g. Balling et al. 1992; Littell et al. 2009). Microclimates can vary widely within a few square kilometres, especially in the mountainous terrain that characterises much of the western US (Holden et al. 2011; Sellers 1965; Thornthwaite 1953), suggesting that coarse-resolution climate division data may not be representative of conditions at remote wildfire locations, as was noted by Westerling et al. (2002).

Recent efforts have produced gridded weather datasets with a resolution of several kilometres, such as the ones used in this study, by applying physically and statistically based algorithms to weather station records (Daly et al. 1994b; Thornton et al. 2012; Abatzoglou 2013). Such datasets have made more detailed analysis possible by avoiding the spatial limitations of climate division datasets and the often temporally sporadic and spatially non-uniform data from weather stations. Gridded datasets at $4-8-\mathrm{km}$ resolution cannot account for all microclimate variability, but represent an advance in this effort.

Below, we briefly describe the calculation of each index and previous work relating this index to fire occurrence. Throughout this manuscript, we qualitatively define the strength of correlations as follows: weak $\left(R^{2}<0.45\right)$, moderate $\left(0.45<R^{2}<0.8\right)$ or strong $\left(0.8 \leq R^{2} \leq 1\right)$.

\section{Palmer Drought Severity Index (PDSI)}

Palmer (1965) outlined calculation of his drought metric as 'a first step toward understanding drought,' but the metric has since become widely institutionalised, especially for estimating agricultural drought. Positive values of PDSI suggest wetter-than-normal conditions, and negative values suggest drought $(-1=$ mild drought,$-2=$ moderate drought, $-3=$ severe drought and $-4=$ extreme drought) (Palmer 1965). The PDSI uses a water balance method that adds precipitation to soil moisture in the top two layers of soil, whereas a simple temperature-driven evapotranspiration algorithm (Thornthwaite 1948) removes it. The calculation of PDSI is autoregressive, based on a portion of the current month's value and the preceding value (Guttman 1998). Thus, PDSI has no inherent time scale, with PDSI values having different 'memories' varying from 2 to more than 9 months depending on the location (Guttman 1998). The spatial scale of PDSI also varies, because the index can be calculated for a single weather station or several stations may be averaged, as in the case of climate division data.

Criticisms of the PDSI are numerous. The algorithm lacks information on important drivers of evapotranspiration, vegetation curing and dead fuel moisture, including relative humidity, solar radiation and wind speed (Sheffield et al. 2012). All precipitation is assumed to be rain, meaning the algorithm is potentially ill-suited for areas where a significant proportion of the precipitation is snowfall. Hence, PDSI has been found to be only weakly to moderately correlated with soil moisture ( $r=0.5-0.7$, equivalent to $R^{2}=0.25-0.49$ ), with the strongest correlation in late summer and autumn, corresponding with fire season in much of the western US (Dai et al. 2004). Owing to data and processing limitations, Palmer developed the index for nine climate divisions in the Midwest, resulting in empirically derived constants that are not locally calibrated for other locations (Palmer 1965). Consequently, the PDSI's value has been found to vary across precipitation regimes, with a single value having different meanings in different areas (Guttman et al. 1992; Guttman 1998). In addition, PDSI values are sensitive to the time period used to calibrate the metric (Karl 1986).

Despite these shortcomings and lack of a clear mechanism relating PDSI to fire occurrence, the PDSI is the index most commonly used to assess drought in the fire literature (Table 1; Baisan and Swetnam 1990; Swetnam and Betancourt 1998; Hessl et al. 2004; Heyerdahl et al. 2008b). For fire history studies, PDSI is often the best available metric because of finerscale reconstructions $\left(1^{\circ}\right)$ than those available for precipitation and temperature (generally $2.5^{\circ}$ ). Current-season PDSI values have been related to contemporary fire occurrence in some ecosystems of the western US, although correlations are rarely strong (Table 1).

\section{Monthly precipitation totals (PPT)}

Monthly precipitation amount has been used in several studies as a metric relating drought to fire occurrence. This metric is simple to measure and calculate; however, because precipitation regimes vary across climatic regions, amounts must be normalised to local records in order to indicate departure from normal conditions. Littell et al. (2009) found seasonal precipitation to be a significant factor in multivariate models predicting area burned for some but not all ecoregions in the 
Table 1. Review of literature relating drought and precipitation indices calculated from weather records to area burned in the western US during the modern era

Studies utilise fire records kept by US Department of Interior National Park Service, Bureau of Land Management, Bureau of Indian Affairs, US Department of Agriculture Forest Service, states and private landowners. Palmer Drought Severity Index (PDSI), Energy Release Component for fuel model G (ERC(G))

\begin{tabular}{|c|c|c|c|}
\hline Region & Authors & Years & Statistic relating drought index to fire occurrence \\
\hline $\begin{array}{l}\text { Yellowstone } \\
\text { National Park, Wyoming, US }\end{array}$ & Balling et al. (1992) & $1895-1990$ & $\begin{array}{l}\text { PDSI for two adjacent climate divisions. Pearson product-moment correla- } \\
\text { tion }(r) \text {, between area burned and summer PDSI }=-0.04 \text { to }-0.33 \text {, for } \\
\text { antecedent winter PDSI }=-0.14 \text { to }-0.35 \text {, for antecedent year PDSI }= \\
-0.12 \text { to }-0.36 \text {, for antecedent } 2 \text { years PDSI }=-0.12 \text { to }-0.38 \text {. Spear- } \\
\text { man's Rank between area burned and summer PDSI }=-0.55 \text { to }-0.6 \text {, for } \\
\text { antecedent winter PDSI }=-0.23 \text { to }-0.27 \text {, for antecedent year PDSI }= \\
-0.2 \text {, for antecedent } 2 \text { years PDSI }=-0.18 \text {. }\end{array}$ \\
\hline $\begin{array}{l}\text { Interior } \\
\text { Western US }\end{array}$ & Collins et al. (2006) & $1926-2002$ & $\begin{array}{l}\text { Average PDSI calculated for } 3 \text { regions }(1=\mathrm{MT}, \mathrm{ID}, \mathrm{WY} ; 2=\mathrm{NV}, \mathrm{UT} \text {; } \\
3=\mathrm{AZ}, \mathrm{NM}) \text { based on averaging PDSI value for each state. Correlations } \\
\text { between area burned and PDSI were: } R^{2}=0.27-0.43 \text { for current year; } \\
R^{2}=0.44-0.67 \text { for model including current year and } 2 \text { years antecedent }\end{array}$ \\
\hline Western US & Littell et al. (2009) & $\begin{array}{l}1916-2003 \text { and } \\
1980-2003\end{array}$ & $\begin{array}{l}\text { Forward selection regression used to parameterise generalised linear models } \\
\text { based on seasonal precipitation, temperature and PDSI for current and } \\
\text { antecedent year; dependent variable was annual area burned by ecopro- } \\
\text { vince, } R^{2}=0.33-0.87\end{array}$ \\
\hline $\begin{array}{l}\text { National Forests } \\
\text { in north-western } \\
\text { California, US }\end{array}$ & Miller et al. (2012) & $\begin{array}{l}1910-1959 \text { and } \\
1987-2008\end{array}$ & $\begin{array}{l}\text { Regression models predicted number of fires based on summer PDSI (June, } \\
\text { July and August) }\left(R^{2}=0.37\right) \text { and total annual area burned }\left(R^{2}=0.37\right) \text { for } \\
\text { the first time period. For the later time period, total precipitation in June, } \\
\text { July and August was correlated with number of fires }\left(R^{2}=0.60\right) \text { and total } \\
\text { annual area burned }\left(R^{2}=0.54\right) \text {. }\end{array}$ \\
\hline $\begin{array}{l}\text { Idaho and western } \\
\text { Montana, US }\end{array}$ & Morgan et al. (2008) & $1900-2003$ & $\begin{array}{l}\text { Spearman's rank correlation between annual area burned and climate-divi- } \\
\text { sion temperature and precipitation. Summer precipitation: } r=-0.49 \\
\text { Summer temperature (normalised): } r=0.59\end{array}$ \\
\hline $\begin{array}{l}\text { Two National } \\
\text { Forest groups in } \\
\text { southern Oregon } \\
\text { and northern } \\
\text { California, US }\end{array}$ & Trouet et al. (2009) & $1973-2005$ & $\begin{array}{l}\text { National Forests clustered into two groups with similar temporal sequences } \\
\text { of area burned. Daily ERC }(\mathrm{G}) \text { was averaged to produce a seasonal value } \\
\text { for July-August-September. Correlation }(r) \text { between annual area burned } \\
\text { and seasonal ERC }(\mathrm{G})=0.32-0.4\end{array}$ \\
\hline US West & Westerling et al. (2003) & $1980-2000$ & $\begin{array}{l}\text { Monthly PDSI values are 'the average of values interpolated from US cli- } \\
\text { mate divisions' onto a } 1 \times 1^{\circ} \text { grid. Pearson's correlation }(r) \sim-0.7-0.8 \text {. } \\
\text { (Note: lagged positive correlations in arid regions may indicate abundant } \\
\text { moisture for fine fuel growth.) }\end{array}$ \\
\hline
\end{tabular}

western US, with negative summer precipitation included in models for 7 of 16 ecoregions. Balling et al. (1992) found total annual precipitation had a Spearman's rank correlation of -0.52 to -0.54 with area burned in Yellowstone National Park, a stronger correlation than they found with PDSI (Table 1).

\section{Standardised Precipitation Index (SPI)}

The SPI is calculated as "the difference of precipitation from the mean for a specified time period divided by the standard deviation' (McKee et al. 1993); where precipitation amounts are not normally distributed, they must be first converted to a normal distribution (Lloyd-Hughes and Saunders 2002). Benefits of the SPI include: (1) it can be used to derive probability of precipitation deviation, (2) it is normalised, so wet and dry climates are represented in similar fashions (McKee et al. 1993), (3) SPI spectra exhibit similar patterns at all locations, meaning the values are comparable across regions (Guttman 1998) and (4) the index can be calculated for any time length in order to capture short- or long-term drought. Despite the advantages of the SPI, we found only one study relating SPI to fire occurrence: Fernandes et al. (2011) found strong correlations between summer 3-month SPI (SPI3) and anomalies in fire incidence in the Western Amazon.

\section{Energy Release Component (ERC)}

The Energy Release Component (ERC), an index in the US National Fire Danger Rating System (NFDRS), provides an approximation of dryness based on estimates of fuel moisture (Andrews et al. 2003). ERC is a continuous variable calculated from a suite of meteorological and site variables, including relative humidity, temperature, precipitation duration, latitude and day of year (Cohen and Deeming 1985). ERC is calculated daily and is thus more dynamic than current implementations of PDSI and SPI, because it is sensitive to daily relative humidity and precipitation timing and duration (i.e. large rain events cause a significant reduction in ERC). ERC calculation is also affected by fuel loadings in different size classes. For example, in this study, ERC was calculated for fuel model $G$, which includes a substantial loading of large dead fuels as well as fine fuels (Bradshaw et al. 1983; Andrews et al. 2003). Owing to the heavy weighting of large dead fuels, ERC $(\mathrm{G})$ is mainly driven by weather conditions during the previous 1.5 months, which is 
the time it takes for dead woody debris $7.6-20.3 \mathrm{~cm}$ (3-8 inches) in diameter (also called 1000-h fuels) to mostly equilibrate to constant ambient conditions (Fosberg et al. 1981).

$\mathrm{ERC}(\mathrm{G})$ has been shown to have a strong relationship with fire occurrence in Arizona: the probability of fire increases with $\mathrm{ERC}(\mathrm{G})$, and can be quantified with logistic regression (Andrews and Bevins 2003; Andrews et al. 2003). Therefore, the ERC $(G)$ is used by US federal land agencies both operationally (Predictive Services) and in simulation models that predict fire size and probability, including FSPro and FSim (Finney et al. $2011 a, 2011 b$ ). However, the parameters of the logistic regression relating ERC(G) and fire occurrence vary with location, suggesting that fires are likely to ignite at different ERC(G) values in different areas due to variations in climate and fuels. For example, fuels tend to burn at a much lower (moister) ERC (G) on Washington's Olympic Peninsula where relative humidity is higher and temperatures are lower during fire season, than in the Great Basin where relative humidity is lower and temperatures are higher. Thus, $\mathrm{ERC}(\mathrm{G})$ should be regarded as a relative index; current $\mathrm{ERC}(\mathrm{G})$ values must be compared to historic values in the same location, as well as local fire occurrence information, in order to interpret them correctly (Schlobohm and Brain 2002).

\section{Associating fire occurrence and weather data}

Each fire's location was assigned to the latitude and longitude at the centroid of its perimeter, and the discovery date was used as a proxy for ignition date. For each fire, we identified the closest pixel of weather data, in both space and time. For monthly indices (PPT, PDSI and all SPIs), we queried the spatially closest pixel during the month of the fire's discovery. Values of monthly indices are based on conditions at the end of each month. We queried the daily $\mathrm{ERC}(\mathrm{G})$ data to identify the ERC (G) of the closest pixel on the fire's discovery date, as well as the 6 days following, and averaged these seven daily ERC(G) values. In the absence of data on containment dates and daily fire progression, we assumed that these first 7 days were critical to fire spread. This assumption may not always hold true, because some large fires, especially those ignited by lightning under moderate conditions, may grow slowly for a period of weeks until a weather event spurs their growth. However, we were hesitant to use an analysis window longer than 7 days for $\mathrm{ERC}(\mathrm{G})$ because this would increase the chance of erroneously incorporating low ERC(G) values associated with weather events that curtailed fire growth.

\section{Statistical analyses}

Empirical distributions of indices for fire v. all conditions

The empirical frequency distributions of indices vary. For example, the SPI is normally distributed and centred at zero, with more than two-thirds of values between -1 and 1 , indicating relatively normal conditions. Therefore, if fires occurred at random with respect to this index, from a purely probabilistic standpoint, fires would be more likely to occur at values close to zero than at extreme values of the index simply because mild values occur more often by an order of magnitude. The same is true for PDSI: PDSI values signifying mild drought also occur much more frequently than extreme values. This property of
PDSI may be why some studies have found that synchronous fires tend to occur at PDSI values signifying mild (frequently occurring) rather than extreme (rarely occurring) drought (e.g. Baisan and Swetnam 1990; Hessl et al. 2004).

To remove the confounding effect of different empirical distributions in relation to fire occurrence, we tested whether the distribution of each index was significantly different during conditions under which large fires occurred than under all conditions, using two tests based on the empirical frequency distribution (EFD) and the empirical cumulative distribution function (ECDF). To determine the EFD of each index's values, we queried the gridded index data and created a histogram of all pixel values occurring during the study period from 1 January 1984 through 31 December 2008. We used all days of the year rather than attempt to delineate a fire season, because the length of fire season varies spatially across the western US and temporally from year to year. We then created histograms of index values associated with large fire events. For each index, to test whether the means of the two EFDs ('fire' $v$. 'all') were different, we compared the bootstrapped means of the two EFDs, using 500 random samples of $n=1000$ with replacement, and then constructed a $90 \%$ confidence interval around the means. Because many of the empirical distributions are nonnormal, this bootstrapping approach was needed to create a confidence interval around the mean. We chose a sample size of 1000 in order to rectify bias introduced by extremely large ( $n>1 \times 10^{6}$ for 'all' conditions) and unequal ( $n=5976$ for 'fire' conditions) population sizes.

Second, we plotted the ECDF of each index for all values and statistically compared it to values associated with large fires. The null hypothesis was that the two distributions were the same. Because smaller values of PPT, PDSI and SPI indicate drier conditions, the alternative hypothesis we tested was that the ECDF of the metric associated with large fires was greater than that of all values of the metric (if the ECDF is greater, the distribution is shifted to the left, suggesting lower index values). Conversely, higher values of ERC $(\mathrm{G})$ indicate drier conditions, so the alternative hypothesis is that the ECDF of the "fire' distribution is less than that of 'all' conditions (in this case, if the ECDF is less, the distribution is shifted to the right, signifying higher index values). The non-parametric test statistic $D$ measures the maximum separation distance between the two distributions. As $D$ increases, so does the likelihood that the two distributions are from different populations. The KolmogorovSmirnov (KS) test was applied to determine the probability that $D$ occurred by chance. Due again to large and unequal sample sizes, we ran the KS test for 500 samples of $n=1000$ for each index. We then calculated how many times the null hypothesis would have been rejected at $\alpha=0.1$ in order to determine whether the 'fire' and 'all' ECDFs were different. This methodology removes the confounding effect of the different frequency distributions of the indices, and determines whether each metric has power in detecting conditions conducive to large fire events.

\section{Correlations of metrics with large fire occurrence}

In order to remove confounding effects introduced by the distribution of the metric and by variations in microclimate, we converted weather and climate data to percentile-based measures that convey the relative rarity of a given index value for 
each pixel that experienced a fire. Thus, we focused on departure from median precipitation conditions as a metric for severity of dry or wet conditions, as measured by a suite of drought and firedanger indices, rather than attempting to find a definition of drought that applies to all climates in the western US.

For each pixel where a fire occurred, we queried all values during the period of study. These values were then sorted, in order to establish the rank of the index's value during each fire. Ranks were calculated based on the index values as a single pool for all seasons, all months and all years. Ranks were then converted to percentiles. For PDSI, SPIs and PPT, low percentiles (near zero) indicate extremely dry conditions, whereas high percentiles (near 100) indicate wet conditions. For ERC(G), the reverse is true: low percentiles (near zero) indicate fuels with high moisture content, whereas high percentiles (near 100) indicate dry fuels. Each fire was thus assigned a percentile for each index. For example, if the value of PPT for March 1997 ranked 100 th of 200 values, signifying average conditions, the PPT percentile would be 50 . Because each pixel has a different distribution of weather data, we found index percentiles for each individual pixel (therefore, an $\mathrm{ERC}(\mathrm{G})$ value of 57 may indicate 95th percentile conditions in one cell, whereas in another cell the 95th percentile $\operatorname{ERC}(\mathrm{G})$ value may be 89 - but in both cases the 95th percentile value indicates a comparable level of aridity for that microclimate). This methodology is similar to that of Alley (1984), who recommended a similar rank-based approach.

For each metric separately, we summed area burned and number of fires across the western US, binning fires by percentile class (e.g. 1st percentile, 2nd percentile). For example, if there were three fires that occurred during 100 th percentile ERC (G) conditions (a 1000-ha fire that occurred in June 2000 in Arizona, a 1200-ha fire during August 2003 in Montana and a 1500-ha fire in southern California in November 2008) then the total area burned during 100 th percentile ERC $(\mathrm{G})$ conditions would be 3700 ha. Essentially, the output is a histogram of area burned with 100 bins where each index percentile corresponds to a bin. The relationship of index percentiles to total area burned was then quantified using linear regression, and evaluated by means of regression analysis $\left(R^{2}\right)$ and tests of significance ( $P$-values). Note that these correlations are based on index values during time periods when a fire occurred. The same methodology was repeated to produce linear models relating number of fires to index percentiles.

\section{Results}

Empirical distributions of indices for 'fire' $\mathrm{v}$. 'all' conditions Empirical frequency distributions (EFDs) of drought indices are varied, and include bimodal, normal and right-skewed (Fig. 3). The EFD of PDSI is bimodal, because of the fact that the index value is reset at the end of a drought or pluvial episode, resulting in a dip in the frequency of the metric at values near zero (Palmer 1965). Mild to moderate PDSI values $(-2$ to +2$)$ occur most frequently in our dataset, with extreme values (e.g. -5 or +5 ) occurring very rarely, indicating the rarity of extreme drought and wet conditions as recorded by this index (Fig. $3 c$ ). Based on visual inspection of the graph, the distribution of PDSIs associated with large fire occurrence is shifted slightly to the left of the distribution of all PDSIs, indicating that fires tend to occur during lower PDSIs. The PDSI values most commonly associated with large fires are -0.5 to -2 , indicating mild drought. The fact that most fires occur at values of PDSI indicating mild drought does not necessarily imply that mild drought is more conducive to large fire than extreme drought; rather, values of the index near zero occur much more frequently, with a relatively small number of months during which fires could potentially occur at rare extreme values of the index. This result also illustrates that extreme drought that cumulates over prolonged periods of moisture deficit is not a prerequisite for fire occurrence. Instead, the proclivity for fire occurrence during mild drought conditions as assessed by the PDSI, may explain why years of fire synchrony tend to occur during years of mild-moderate rather than extreme drought simply because mild droughts occur much more frequently (Baisan and Swetnam 1990; Balling et al. 1992; Swetnam and Betancourt 1998; Westerling et al. 2003; Hessl et al. 2004; Heyerdahl et al. 2008a).

The EFD of ERC $(\mathrm{G})$ is characterised by frequent occurrence of moderate $\mathrm{ERC}(\mathrm{G})$ values, whereas high values indicating extremely dry conditions are rare (Fig. $3 a$ ). Zero values occur most frequently (zero is assigned to indicate snow or high fuel moistures that preclude burning). The distribution of ERC(G) values associated with large fire events is markedly different from that of $\mathrm{ERC}(\mathrm{G}) \mathrm{s}$ as a whole, being skewed towards the higher ERC $(G)$ values typically associated with dry fuels.

In contrast to PDSI and $\operatorname{ERC}(G)$, the EFD of monthly precipitation values (PPT) is heavily right-skewed, with the lowest precipitation values being most common (Fig. $3 b$ ). The distribution of PPT during large fire events is more heavily skewed towards low PPTs than the distribution of PPT during the entire period of study, indicating fire events take place preferentially at lower PPTs.

The EFD of the Standard Precipitation Index is by definition normal because of its calculation, as discussed previously (Fig. $3 d-h$ ). The distribution of SPI3 values under which large fires ignite is shifted towards more negative (drier) values of SPI3 than that of the distribution of the metric as a whole, indicating that large fires tend to burn more frequently under values of SPI3 that indicate drought. However, visual inspection of these figures indicates that this shift weakens as the period tabulated by the metric lengthens, until it is not visible for SPI24 (Fig. 3).

We also performed quantitative testing of the means of the EFDs. Testing of the means indicated that the mean values of $\mathrm{ERC}(\mathrm{G})$, PPT and SPI3 associated with large fires are significantly drier than the mean of all values at the $90 \%$ confidence level (Fig. 4, Table 2). Confidence intervals around the means of the 'fire' and 'all' values distributions for PDSI, SPI6, SPI9, SPI12 and SPI24 overlapped, indicating that the means are not significantly different.

A second method for testing whether the distributions of 'fire' and 'all' conditions are different used the KolmogorovSmirnov test of the $D$ statistic of the empirical cumulative distribution functions (ECDFs; Table 2). These KolmogorovSmirnov tests indicated that the 'fire' distributions of ERC $(G)$ and PPT are significantly different than the distributions of these metrics under all conditions, and strong evidence existed for SPI3 as well (Fig. 5; Table 2). Evidence that the 'fire' distributions of SPI6, SPI9, SPI12 and SPI24 are different from 'all' conditions weakened as the time period tabulated by the metric 

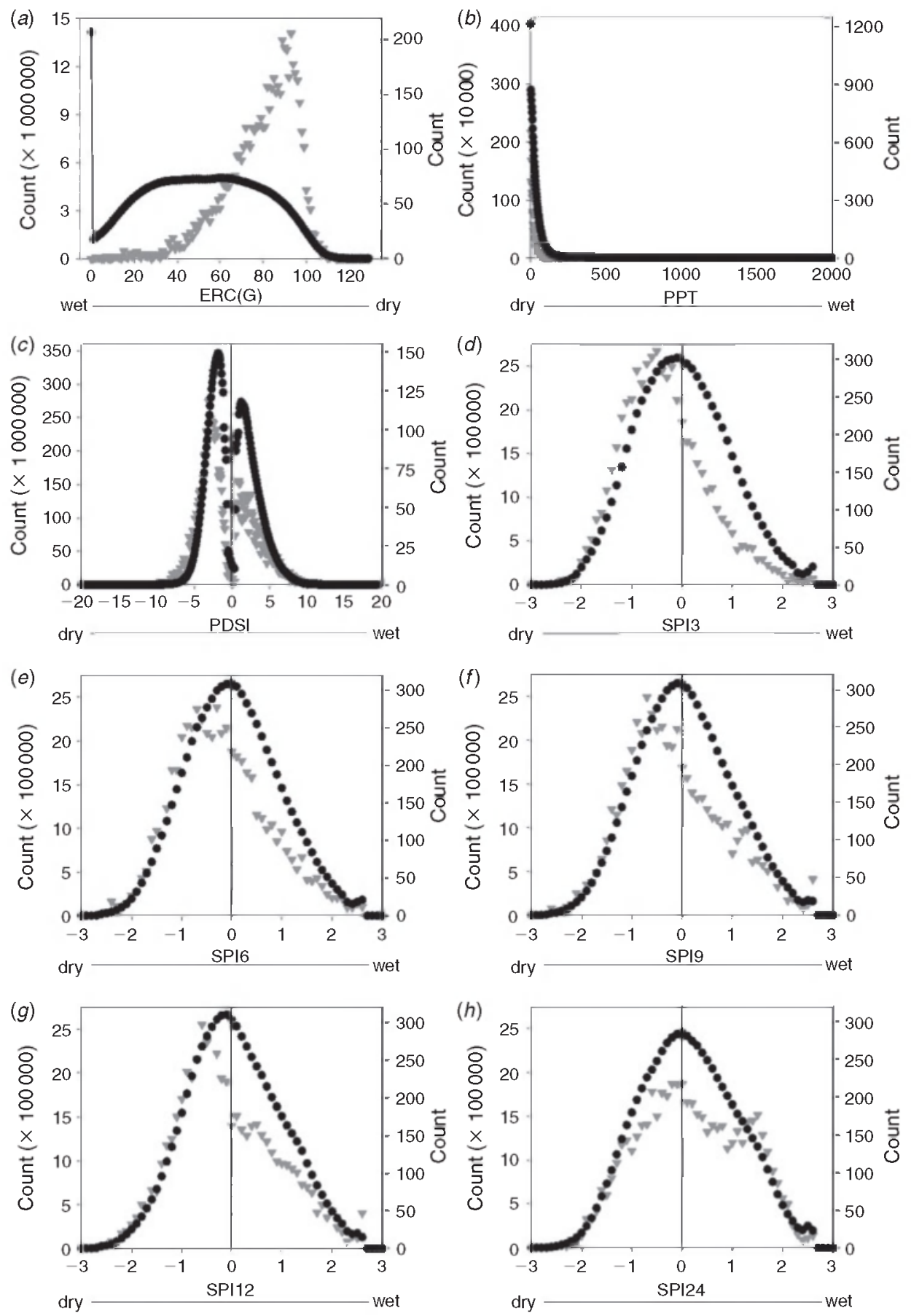

Fig. 3. Empirical frequency distribution (EFD) of index values, 1 January 1984-31 December 2008, in the study area (shown in black) plotted with EFD of index values associated with large fire events (shown in grey). Empirical frequency distribution of some indices is markedly different for fire events than as a whole, suggesting that these indices are related to fire occurrence. (a) Energy Release Component for fuel model G(ERC(G)) (7-day average), (b) monthly precipitation (PPT), (c) Palmer Drought Severity Index (PDSI), (d) Standardised Precipitation Index at 3 months (SPI3), (e) at 6 months (SPI6), $(f)$ at 9 months (SPI9), (g) at 12 months (SPI12) and (h) at 24 months (SPI24).

increased (Table 2; Fig. 5). For PDSI, relatively weak evidence exists that the two distributions are different, and this hypothesis would be rejected by both testing of the means (Fig. 4) and approximately one-third of Kolmogorov-Smirnov statistic tests at $\alpha=0.1$ (Fig. 5; Table 2). Thus, PDSI is not strongly related to large fire occurrence.

Taken as a whole, these results suggest that shorter-term indices (ERC(G), PPT and SPI3) are more strongly associated 

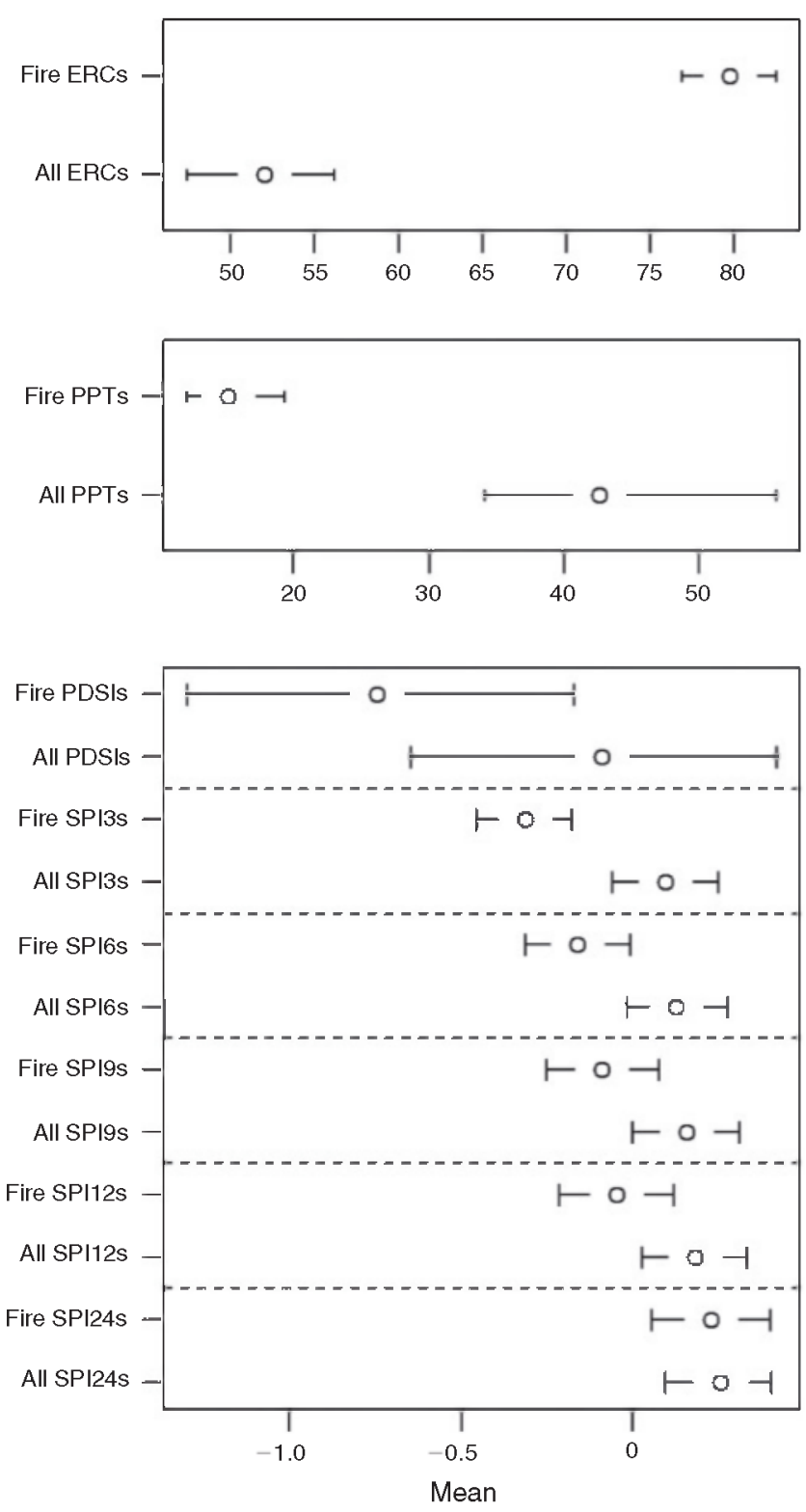

Fig. 4. The $90 \%$ confidence interval around the mean value of indices, for all index values during 1 January 1984-31 December 2008 and for index values associated with large fires events. Bootstrapped mean was calculated on a sample with replacement, with sample size $=1000$, and sample conducted 500 times. Pairs of confidence intervals overlapped for PDSI, SPI6, SPI9, SPI12 and SPI24, meaning there is not statistical evidence that the means are different under conditions when large fires occurred. Monthly precipitation (PPT), Energy Release Component (ERC), Palmer Drought Severity Index (PDSI) and Standardised Precipitation Index at 3-, 6-, 9-, 12and 24-month timescales (SPI3-SPI24).

with large fire occurrence than longer-term metrics (PDSI, SPI6, SPI9, SPI12 and SPI24).

\section{Correlations of metrics with large fire occurrence}

The area burned by individual fires was not strongly related to raw index values. Results are shown for $\operatorname{ERC}(G)$ and PDSI, with the pattern being similar for the other metrics (Fig. 6).
The largest fires occur at frequent values of indices (moderate ERC(G), low PPT, moderate PDSI and moderate SPI), rather than the most extreme values. For example, the largest fires did not occur at the highest $\operatorname{ERC}(\mathrm{G}) \mathrm{s}$, which are rare in the record. Large fires occurred more often during the drier phase of the metrics (higher ERC(G)s, negative PDSI and negative SPI); this relationship with SPI is stronger in the shorter phase of this metric (SPI3), and weakens progressively as the duration of the metric becomes longer. In the case of ERC(G), PPT and PDSI, the relationship with fire area is further obscured by the fact that these metrics vary regionally (e.g. a precipitation value of $20 \mathrm{~mm}$ in a month may signify wet conditions in the Great Basin and dry conditions on the Washington Coast). However, by transforming indices to percentile values for each fire, the relationships become more apparent. For example, a scatterplot of $\mathrm{ERC}(\mathrm{G})$ percentile $v$. fire size illustrates that large fires tend to occur when ERC $(G)$ is above the 80th percentile (Fig. 7).

We parameterised linear models relating index percentile to number of large fires (Table 3, Fig. 8) and area burned (Table 4, Fig. 9). For all metrics, correlations between index percentile and number of large fires were stronger than those between index percentile and area burned. Of all metrics, $\mathrm{ERC}(\mathrm{G})$ percentile demonstrated the strongest relationship with area burned (adjusted $R^{2}=0.92$; Table 4; Fig. 9) as well as number of fires (adjusted $R^{2}=0.94 ;$ Fig. 8 ; Table 3 ). Number of fires and area burned increased exponentially with $\operatorname{ERC}(G)$ percentile. PPT percentile (Figs 8, 9, Tables 3, 4) demonstrated almost as strong a relationship with number of fires and area burned as ERC(G) (for number of fires, adjusted $R^{2}=0.93$; for area burned, adjusted $R^{2}=0.89$ ). SPI3 percentile (Figs 8, 9, Tables 3,4 ) had a strong correlation with number of fires (adjusted $R^{2}=0.83$ ) and moderate correlation with area burned (adjusted $R^{2}=0.70$ ). For SPI6, 9, 12 and 24 percentile (Fig. 9, Table 4), the models explained less than half of the variability in area burned, indicating a weak relationship between area burned and these indices. Correlations with number of fires were somewhat stronger, with models explaining more than half the variability in the data for SPI6, 9 and 12 percentile, declining with the time period measured by the index. PDSI percentile also showed a weak relationship with area burned (adjusted $R^{2}=0.34$, Fig. 9, Table 4), except perhaps at extremely low PDSI values $(0-20$ th percentile), where area burned increases with drought severity. In addition, PDSI percentile had a weak relationship with number of large fires (adjusted $R^{2}=0.30$, Fig. 8, Table 3). Based on these results, we concluded that $\mathrm{ERC}(\mathrm{G})$ percentile is the index with the most power in predicting large fire occurrence across the western US, followed closely by PPT percentile.

\section{Discussion}

We found strong correlations between fire occurrence (defined as total area burned and total number of fires) and certain drought and fire danger indices across the western US, indicating that models based on a single metric can account for over $90 \%$ of the variability in number of large fires and area burned across a large region, once metrics have been normalised to account for local climate. We therefore concluded that our methodology was successful in reducing the effect of 
Table 2. Statistics comparing empirical distributions of indices during large fire events with those during all conditions The null hypothesis $\left(H_{o}\right)$ was that the two distributions were the same. The alternative hypothesis $\left(H_{a}\right)$ for Palmer Drought Severity Index (PDSI), Standardised Precipitation Index (SPIs) and monthly precipitation (PPT) was that the empirical cumulative distribution function (ECDF) of the index during fires is greater than that of all values; for Energy Release Component for fuel model G(ERC(G)), $H_{a}$ was that the ECDF of ERC(G) associated with fire events is less than that of all ERC(G)s. $H_{o}$ was rejected a higher percentage of the time for shorter-term metrics (at $\alpha=0.1$ ), constituting evidence that large fire occurrence is more strongly related to shorter-term metrics. The $D$ statistic measures the maximum separation distance between the two distributions, with higher values suggesting higher likelihood that the two distributions are different. Data in italic show strong evidence for differences between the 'fire' and 'all' distributions

\begin{tabular}{|c|c|c|c|c|c|}
\hline Index & Median of means (fire) & Median of means (all) & Means different based on $90 \% \mathrm{CI}$ ? & $D($ median $)$ & Percentage of tests in which $H_{o}$ rejected \\
\hline $\operatorname{ERC}(\mathrm{G})$ & 79.80 & 52.1 & Yes & 0.52 & 100.0 \\
\hline PPT & 15.10 & 42.6 & Yes & 0.36 & 100.0 \\
\hline SPI3 & -0.30 & 0.1 & Yes & 0.26 & 95.5 \\
\hline SPI6 & -0.20 & 0.1 & No & 0.20 & 78.6 \\
\hline SPI9 & -0.10 & 0.2 & No & 0.20 & 77.8 \\
\hline SPI12 & -0.05 & 0.2 & No & 0.19 & 72.6 \\
\hline PDSI & -0.70 & -0.1 & No & 0.19 & 70.0 \\
\hline SPI24 & 0.23 & 0.26 & No & 0.11 & 18.6 \\
\hline
\end{tabular}
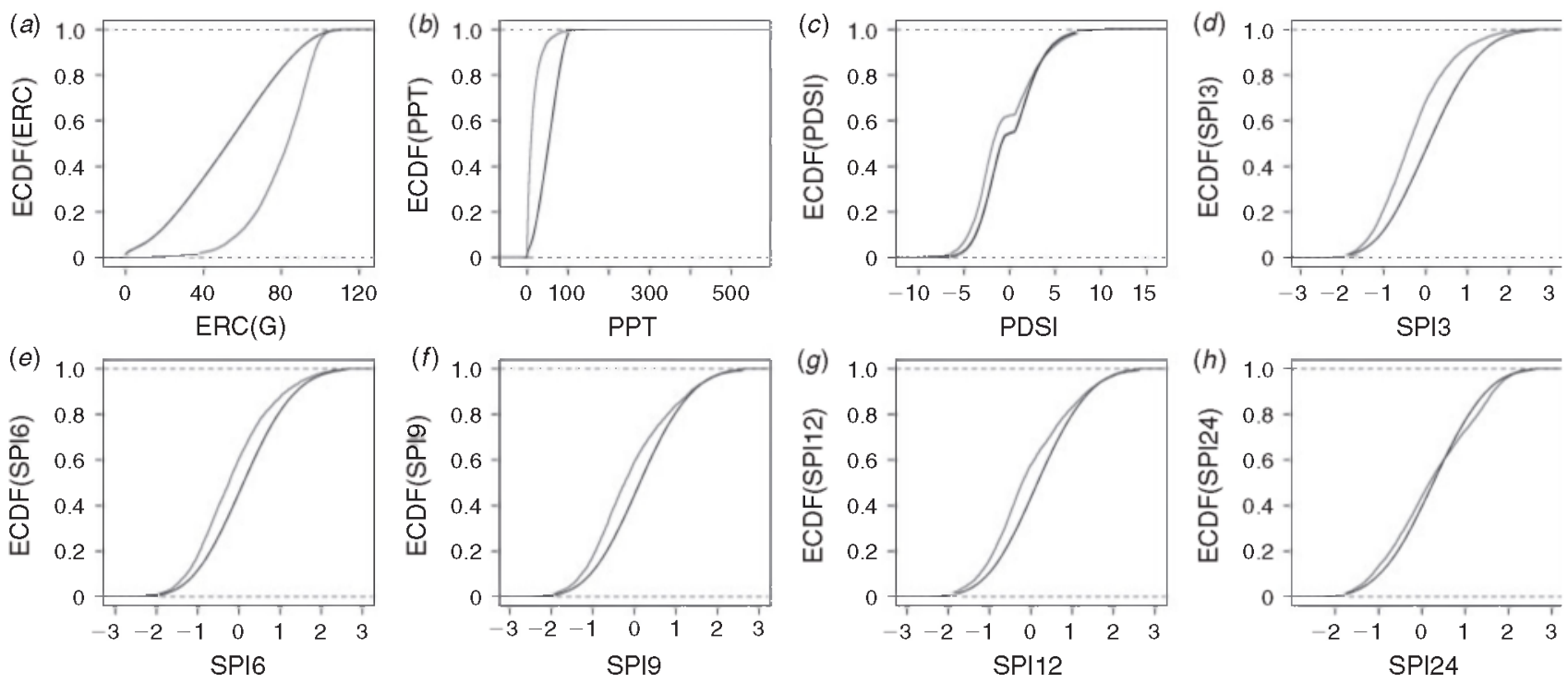

Fig. 5. Empirical cumulative distribution functions (ECDF) of indices, for all conditions and those associated with fires. For fires, $n=5976$ ( $s h o w n$ in grey) Owing to processing limitations, $1 \times 10^{6}$ values were randomly sampled from the index values to create the ECDF of 'all' values (shown in black). (a) Energy Release Component for fuel model G (ERC(G)) (7-day average), (b) monthly precipitation (PPT), (c) Palmer Drought Severity Index (PDSI), (d) Standardised Precipitation Index at 3 months (SPI3), (e) at 6 months (SPI6), $(f)$ at 9 months (SPI9), $(g)$ at 12 months (SPI12) and $(h)$ at 24 months (SPI24).

confounding factors discussed in the Introduction and Methods sections, by: (1) accounting for the empirical distribution of indices by normalising metrics to percentile, (2) removing the relative meanings of some indices by normalising them to local climate, (3) using a consistent georeferenced dataset for fire occurrence provided by the MTBS project, which reduced problematic fire records and (4) utilising gridded index data to more closely represent weather and climate conditions near remote fire locations than datasets with coarser resolutions.

Once metrics were normalised to percentile, we found that metrics based on the previous 1-3 months of weather data had strong correlations with both total area burned and number of large fires, indicating that this time period is critical to producing the conditions conducive to large fires. As the time period tabulated by the metric lengthened, the correlation weakened.
This result indicates the importance of dead fuel moisture in promoting or retarding the spread of large fires. Dead surface fuels (grass, litter, duff and woody debris) are the primary carrier of surface fires, and provide the intensity necessary for surface fires to transition to crown fires (Van Wagner 1977). Fine fuels such as grass are frequently referred to as $1-\mathrm{h}$ fuels, because they mostly equilibrate to constant ambient conditions within a few hours, whereas woody debris $7.6-20.3 \mathrm{~cm}$ (3-8 inches) in diameter falls into the 1000-h category, meaning it takes $\sim 40$ days to mostly equilibrate with constant environmental conditions (Fosberg et al. 1981). Dead fuel moistures therefore largely depend on weather conditions within the previous month and a half. It follows, therefore, that monthly precipitation totals (PPT), which were strongly related to area burned and number of fires in the western US, are a major driver of dead fuel 

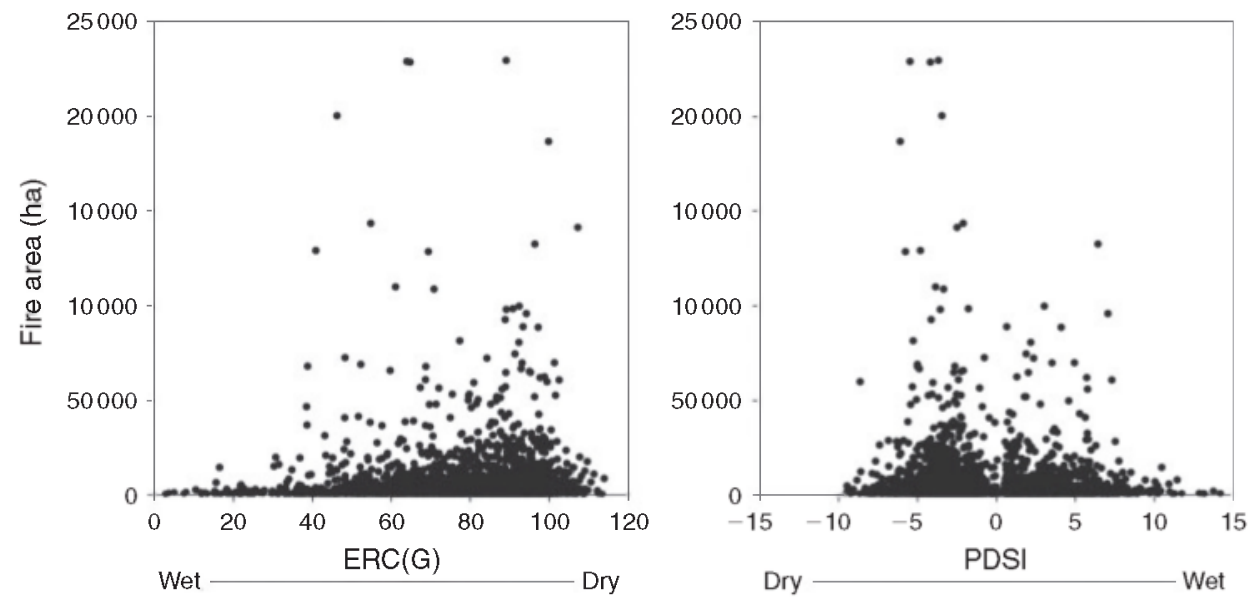

Fig. 6. Plot of fire area $v$. Energy Release Component for fuel model G (ERC(G)) (left), and fire area $v$. Palmer Drought Severity Index (PDSI) (right).

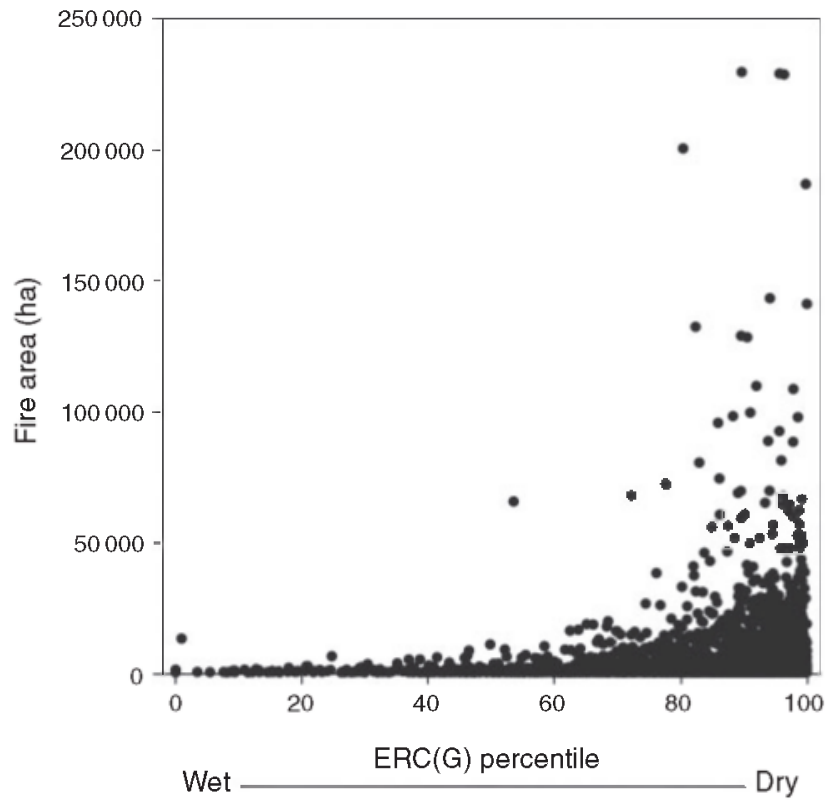

Fig. 7. Plot of fire area $v$. Energy Release Component for fuel model G $(\mathrm{ERC}(\mathrm{G}))$ percentile.

moisture values. Because $\mathrm{ERC}(\mathrm{G})$ contains fuels of all size classes, including a heavy weighting of 1000-h fuels (Bradshaw et al. 1983; Andrews et al. 2003), this index also captures trends in fuel moistures largely based on weather during the previous month and a half. ERC $(G)$ has two other properties which likely caused it to have a stronger relationship with fire occurrence than other indices in this study. First, ERC(G) calculation includes relative humidity and solar radiation terms, which are important determinants of fuel moisture and vegetation curing. As vegetation cures, it becomes more readily available to burn and thus contribute to increased fire intensity and rate of spread (Scott and Burgan 2005). Second, ERC(G) is calculated on a daily timestep and can capture timing of precipitation events, which affect the potential for fires to grow. Of the indices
Table 3. Linear models relating index percentiles to number of large fires

n, number of large fires; $E R C_{-} p c t$, Energy Release Component for fuel model G (ERC(G)) percentile; $P P T$ p $p$ t, monthly precipitation (PPT) percentile; PDSI_pct, Palmer Drought Severity Index (PDSI) percentile; SPI3_pct, Standardised Precipitation Index (SPI) at 3-month percentile; SPI6_pct, SPI6 percentile; SPI9_pct, SPI9 percentile; SPI12_pct, SPI12 percentile; SPI24_pct, SPI24 percentile; $R^{2}$ adjusted $R^{2}$ of model

\begin{tabular}{llc}
\hline Index & \multicolumn{1}{c}{ Model } & $R^{2}$ \\
\hline ERC(G) & $\log _{10} n=0.02768 \times\left(E R C_{p c t}\right)-0.2333$ & 0.94 \\
PPT & $\log _{10} n=-0.01389 \times\left(P P T_{p c t}\right)+2.303$ & 0.93 \\
PDSI & $\log _{10} n=-0.002438 \times\left(P D I_{p c t}\right)+1.878$ & 0.30 \\
SPI3 & $\log _{10} n=-0.006487 \times\left(S P I 3_{p c t}\right)+2.058$ & 0.83 \\
SPI6 & $\log _{10} n=-0.003710 \times\left(S P I 6_{p c t}\right)+1.944$ & 0.68 \\
SPI9 & $\log _{10} n=-0.002978 \times\left(S P I 9_{p c t}\right)+1.910$ & 0.52 \\
SPI12 & $\log _{10} n=-0.002813 \times\left(S P I I 2_{p c t}\right)+1.903$ & 0.52 \\
SPI24 & $\log _{10} n=-0.000473 \times\left(S P I 24_{p c t}\right)+1.743$ & 0.012 \\
\hline
\end{tabular}

analysed, only ERC(G) captures daily weather, because other indices are summed over monthly intervals. However, ERC $(G)$ calculation is more complex than that of PPT, which performed nearly as well, indicating that PPT could be used in situations where time, processing power or data inputs are limited. SPI3 did not perform as well as $\mathrm{ERC}(\mathrm{G})$ or PPT, but was strongly correlated with number of large fires and moderately correlated with area burned in the western US. Given that SPI3 is based on precipitation during a 3 -month period, we expect that it would have a moderately strong relationship with fuel moistures.

Indices based on longer timeframes had weaker or no relationship with fire occurrence. This result was likely due to the fact that longer-term indices do not strongly reflect recent precipitation and thus have weaker relationships with dead fuel moistures. For example, because PDSI is autoregressive, summer PDSI values will reflect antecedent conditions and are affected by winter-spring precipitation. Similarly, SPI9 for October-June could have an equivalent value for a 9-month period encompassing a dry October-March followed by a wet 

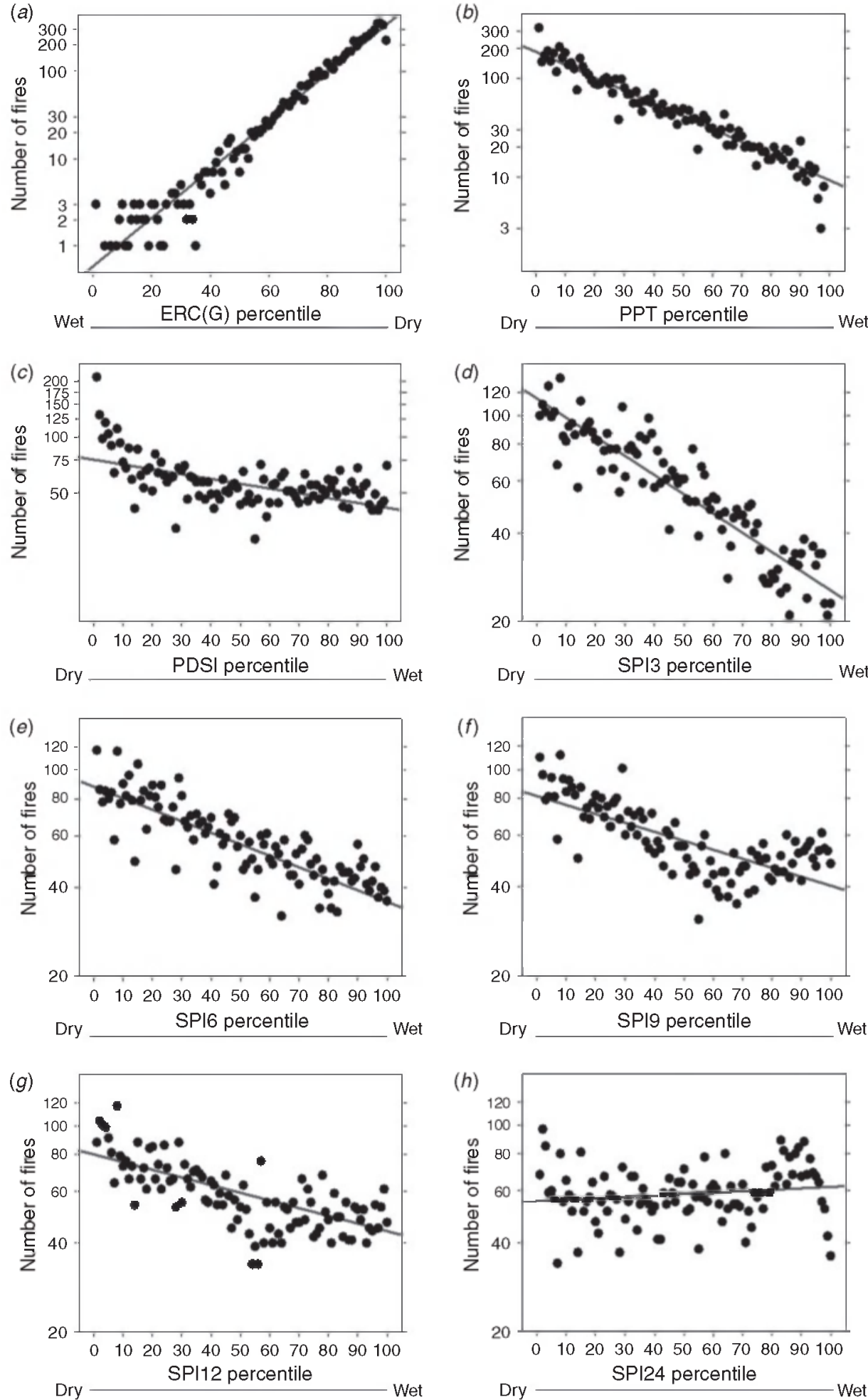

Fig. 8. Plot of total number of fires, summed by index percentile. Each point represents the total number of fires that occurred in that percentile, with 100 percentile bins. (a) Energy Release Component for fuel model G $(\mathrm{ERC}(\mathrm{G})),(b)$ monthly precipitation (PPT), (c) Palmer Drought Severity Index (PDSI), (d) Standardised Precipitation Index at 3 months (SPI3), $(e)$ at 6 months (SPI6), $(f)$ at 9 months (SPI9), $(g)$ at 12 months (SPI12) and $(h)$ at 24 months (SPI24). 
Table 4. Linear models relating drought index percentiles to area burned

$A$, area burned; $E R C_{\text {p }}$ ct, ERC(G) percentile; $P P T$ pct, PPT percentile; PDSI_pct, PDSI percentile; SPI3_pct, SPI3 percentile; SPI6_pct, SPI6 percentile; SPI9_pct, SPI9 percentile; SPII2_pct, SPI12 percentile; $S P I 24 \_p c t$, SPI24 percentile; $R^{2}$, adjusted $R^{2}$ of model

\begin{tabular}{llr}
\hline Index & \multicolumn{1}{c}{ Model } & $R^{2}$ \\
\hline ERC(G) & $\log _{10} A=0.03551 \times\left(E R C_{p c t}\right)+2.592$ & 0.92 \\
PPT & $\log _{10} A=-0.01862 \times\left(P P T_{p c t}\right)+5.984$ & 0.89 \\
PDSI & $\log _{10} A=-0.003780 \times\left(P D S I_{p c t}\right)+5.4875$ & 0.25 \\
SPI3 & $\log _{10} A=-0.009755 \times\left(S P I 3_{p c t}\right)+5.738$ & 0.70 \\
SP16 & $\log _{10} A=-0.005972 \times\left(S P I 6_{p c t}\right)+5.595$ & 0.46 \\
SP19 & $\log _{10} A=-0.003784 \times\left(S P I 9_{p c t}\right)+5.502$ & 0.28 \\
SP112 & $\log _{10} A=-0.003366 \times\left(S P I 12_{p c t}\right)+5.492$ & 0.23 \\
SP124 & $\log _{10} A=0.000007998 \times\left(S P I 24_{p c t}\right)+5.317$ & -0.01 \\
\hline
\end{tabular}

April-June, as it would for a wet October-March followed by a dry April-June. However, the effect on dead fuel moistures as well as the amount of vegetation that has cured would be extremely different.

The weather conditions surrounding the extensive 1910 fires in Montana and Idaho demonstrate a case where shorter-term metrics would have likely been more strongly correlated with fire occurrence than longer-term metrics. In a 1931 study, the year 1910 was not listed as being among the 10 driest years for either state during the period of record (1895-1930 for Montana and 1898-1930 for Idaho) (Henry 1931). Henry (1931) notes that, 'The dry year 1910 is seemingly in a class by itself' with the onset of the drought being 'quite sudden as compared with the others'. Work by Brown and Abatzoglou (2010) and Diaz and Swetnam (in press) using gridded weather data reinforces these conclusions: an anomalously wet and cool winter was followed by an anomalously dry and warm spring and summer. In the case of 1910, an infamous year of synchronous fires, longer-term metrics such as PDSI, SPI9, SPI12 or SPI24 would likely not have captured the conditions that promoted fire, whereas shorter-term metrics such as ERC(G) or PPT likely would have (Chuck McHugh, pers. comm.).

Although shorter-term fluctuations in precipitation strongly affect dead fuel moistures, longer-term periods of dry weather affect live fuels. As noted above, long periods of dry weather may result in mortality and curing of some live fuels, increasing rates of spread and fire intensity (Scott and Burgan 2005). This dynamic occurs seasonally in many ecosystems, but longerthan-average dry periods contribute to additional mortality. In addition, long droughts may reduce live fuel moisture of trees, which likely contributes to crown fire potential. However, live fuel flammability is still not well understood, with current research focussing on differences between new and old foliage and the abundance of flammable compounds, which fluctuate in response to seasonal drivers (Matt Jolly, pers. comm.). Metrics capturing longer time periods may relate in some way to these factors, but further research is needed to measure seasonal fluctuations in live fuel moistures and link them to index values.

Fire suppression has likely affected the relationship of fire occurrence with fuel conditions. Some evidence indicates that the relationship of PDSI and fire occurrence was stronger during the pre-suppression era (Miller et al. 2012), when fires may have burned under more moderate conditions. Prior to European colonisation, Native American burning was common in the US, with many tribes choosing to ignite burns during mild weather conditions in the spring (Lewis 1973). Current fire management policies in the western US tend to eliminate fires that can be suppressed, with suppression more effective under mild and moderate conditions (Finney et al. 2009), leaving fires that escape suppression under the most extreme weather conditions to burn most of the acreage. There are exceptions, including fires that are allowed to burn in remote areas under mild or moderate conditions. Suppression forces can often take advantage of small precipitation events to control or contain fires, with such precipitation events being captured by $\operatorname{ERC}(G)$ calculation. In the pre-suppression era, fires might have continued to grow once these precipitation events ended. MTBS project data do not contain information on suppression efforts, therefore, this factor could not be included in our analysis.

We found stronger correlations between index percentiles and number of large fires than with area bumed. We conclude shortterm drought is a stronger driver of number of large fires than of total area burned, because probability of ignition increases with drier fuel moistures, whereas the area burned by large fires is also affected by other factors responsible for fire growth, including wind, temperature, topography, barriers to spread, fuel type, availability of fine fuels in some ecoregions, suppression tactics and maturity of forest in stand-replacing regimes. We note that individual fire sizes were not strongly related to drought and fire danger indices, likely because of the effect of these factors. It is noteworthy, however, that precipitation indices showed a strong correlation with fire occurrence at the scale of the western US without including these other factors in statistical models.

\section{Conclusions}

The primary goals of this study were to: (1) investigate how shorter-and longer-term drought are related to fire occurrence in the western US by evaluating the strength of the correlation of various drought and fire danger indices with area burned and number of large fires and (2) determine whether a single drought or fire danger index is strongly related to fire occurrence across the western US, because such a metric could be used in predictive modelling of large fires in current fire danger applications, fire history studies and studies predicting future fire occurrence under changing climatic conditions. When converted to a percentile-based measure indicating departure from local median conditions, short-term metrics $\mathrm{ERC}(\mathrm{G})$ and monthly precipitation (PPT) had strong correlations with area burned $\left(R^{2}=0.92\right.$ and 0.89$)$ and number of large fires $\left(R^{2}=0.94\right.$ and 0.93 ) in the western US over the study period (1984-2008). As the temporal scale of indices increased, the strength of their relationship with fire occurrence decreased. A likely reason for this result is that shorter-term metrics are more strongly related to dead fuel moistures, which are largely dependent on weather during the past 1-3 months. Longer-term metrics are not as sensitive to recent precipitation events that affect fuel moistures and thus fire occurrence. Although PDSI is the most commonly used drought metric in fire history studies and in efforts to predict area burned, we found that it is not strongly correlated with area burned $\left(R^{2}=0.34\right.$ for PDSI percentile) or number of large fires $\left(R^{2}=0.30\right)$, likely because of the fact that it is not 
(a)
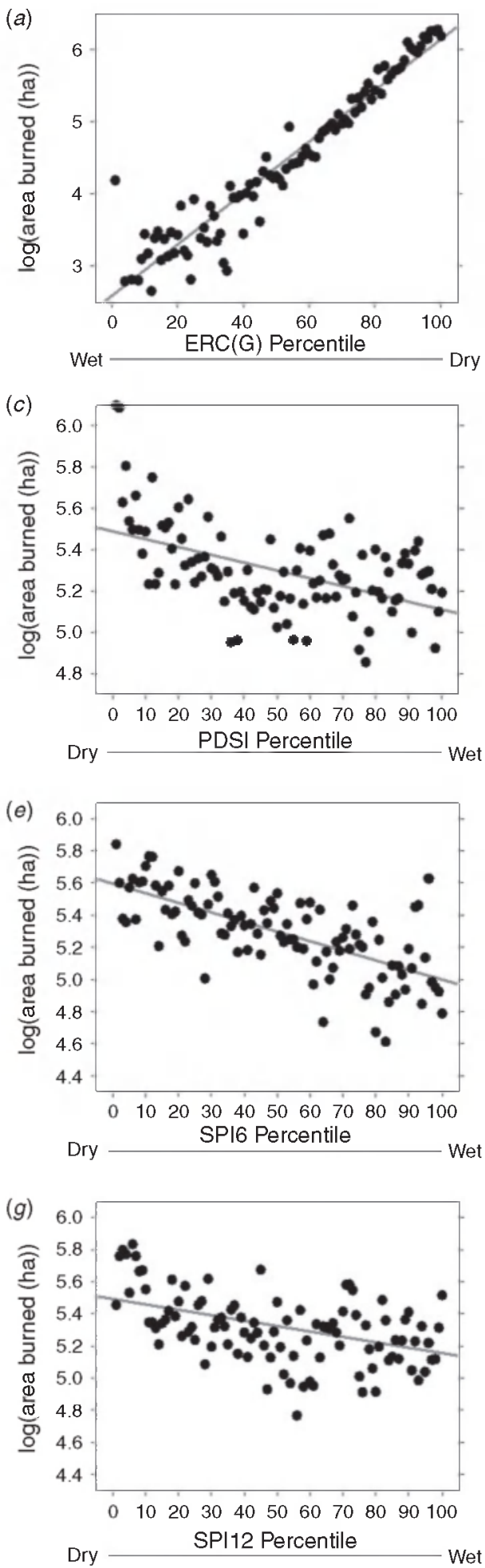
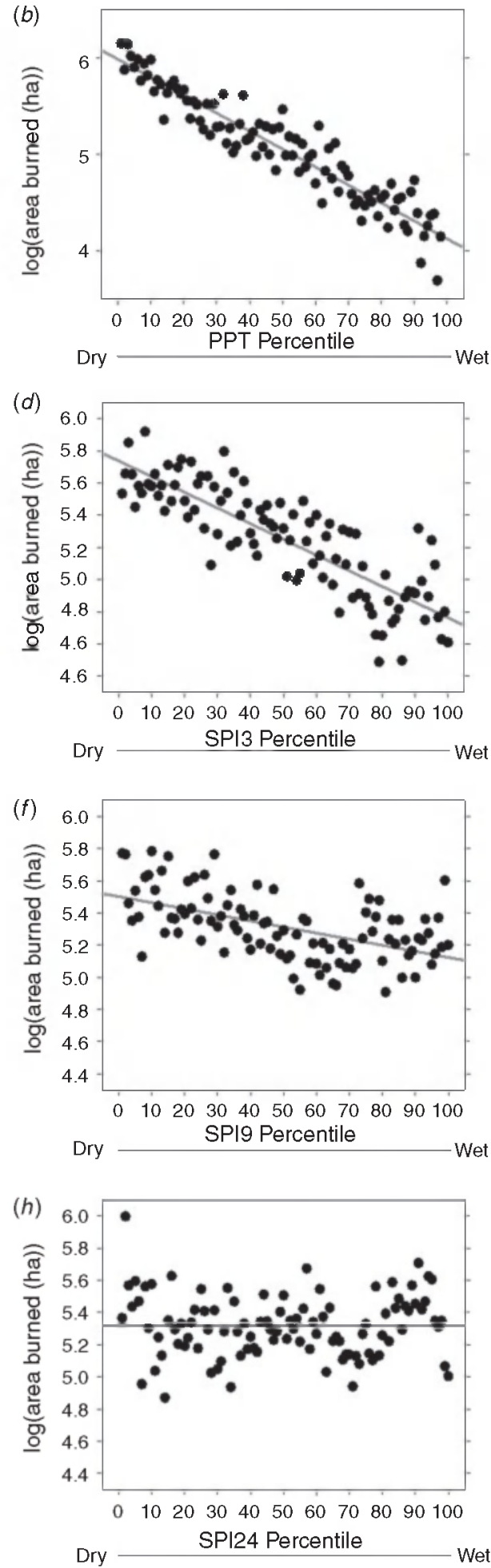

Fig. 9. Plot of sum of area burned, by index percentile. Each point represents the total area burned in that percentile, with 100 percentile bins. (a) Energy Release Component for fuel model G (ERC(G)), (b) monthly precipitation (PPT), (c) Palmer Drought Severity Index (PDSI), (d) Standardised Precipitation Index at 3 months (SPI3), (e) at 6 months (SPI6), $(f)$ at 9 months (SPI9), $(g)$ at 12 months (SPI12) and $(h)$ at 24 months (SPI24). 
strongly related to dead fuel moistures (Dai et al. 2004). We therefore recommend the use of $\operatorname{ERC}(G)$ or the more easily calculated PPT for use in applications that associate precipitation and fire occurrence.

Because ERC $(G)$ and PPT are largely based on weather conditions during the previous month, they are not easily used for long-lead forecasting of fire occurrence, nor can they be used in fire history studies, such as those relying on tree-ring data, without research examining these shorter-term indices and tree growth. Little is currently known about the mechanisms that drive drought, especially during fire seasons, with precipitation anomalies associated with El Niño-Southern Oscillation being more strongly linked to winter than summer precipitation across much of the western US (Ropelewski and Halpert 1986; McCabe and Dettinger 1999). Hence, long-lead forecasting of fire danger is currently challenging, given our result that fire season precipitation is the strongest predictor of fire occurrence. However, if it were possible to predict synoptic patterns that cause negative precipitation anomalies that endure for more than 1 month, areas of high fire danger could in turn be predicted using forecast $\mathrm{ERC}(\mathrm{G})$ and $\mathrm{PPT}$ values.

\section{Acknowledgements}

Karin Riley appreciates financial support from the Jerry O'Neal National Park Service Student Fellowship and University of Montana Transboundary Research Award. This study was also funded in part by the USFS Rocky Mountain Research Station and Western Wildland Environmental Threat Center. Our thanks to Rebecca Bendick and three anonymous reviewers for constructive critiques of this article. Kari Pabst and Jennifer Lecker of the Monitoring Trends in Burn Severity Project gave support regarding MTBS project data. We thank Chuck McHugh for information on the 1910 fires. John Abatzoglou was partially supported by the NSF Idaho EPSCoR Program and by the National Science Foundation under award number EPS-0814387 and the United States Forest Service award number 10-JV-11261900-039.

\section{References}

Abatzoglou JT (2013) Development of gridded surface meteorological data for ecological applications and modelling. International Journal of Climatology 33, 121-131. doi:10.1002/JOC.3413

Abatzoglou JT, Kolden CA (2011) Relative importance of weather and climate on wildfire growth in interior Alaska. International Journal of Wildland Fire 20, 479-486. doi:10.1071/WF10046

Ager AA, Vaillant NM, Finney MA (2010) A comparison of landscape fuel treatment strategies to mitigate wildland fire risk in the urban interface and preserve old forest structure. Forest Ecology and Management 259, 1556-1570. doi:10.1016/J.FORECO.2010.01.032

Alley WM (1984) The Palmer Drought Severity Index: limitations and assumptions. Journal of Climate and Applied Meteorology 23, 1100 1109. doi: $10.1175 / 1520-0450(1984) 023<1100$ :TPDSIL $>2.0 . \mathrm{CO} ; 2$

Andrews PL, Bevins CD (2003) BehavePlus Fire modeling system, version 2: overview. In 'Second International Wildland Fire Ecology and Fire Management Congress', 16-20 November 2003, Orlando, FL. P5.11. (American Meteorological Society: Boston, MA) Available at https:// ams.confex.com/ams/FIRE2003/techprogram/paper_65993.htm [Verified 28 June 2013]

Andrews PL, Loftsgaarden DO, Bradshaw LS (2003) Evaluation of fire danger rating indexes using logistic regression and percentile analysis. International Journal of Wildland Fire 12, 213-226. doi:10.1071/ WF02059

Baisan CH, Swetnam TW (1990) Fire history on a desert mountain range: Rincon Mountain Wilderness, Arizona, USA. Canadian Joumal of Forest Research 20, 1559-1569. doi:10.1139/X90-208
Balling RC, Meyer GA, Wells SG (1992) Relation of surface climate and burned area in Yellowstone National Park. Agricultural and Forest Meteorology 60, 285-293. doi:10.1016/0168-1923(92)90043-4

Bradshaw LS, Deeming JE, Burgan RE, Cohen JD (1983) The 1978 National Fire-Danger Rating System: technical documentation. USDA Forest Service, Intermountain Forest and Range Experiment Station, General Technical Report INT-169. (Ogden, UT)

Brown TJ, Abatzoglou JT (2010) The climate of the Big Blowup. In 'Proceedings of the 3rd Fire Behavior and Fuels Conference', 25-29 October 2010, Spokane, WA. pp. 1-7. (International Association of Wildland Fire, Birmingham, AL)

Brown TJ, Hall BL, Mohrle CR, Reinbold HJ (2002) Coarse assessment of federal wildland fire occurrence data. Report for the National Wildfire Coordinating Group. Desert Research Institute, CEFA Report 02-04. (Reno, NV)

Calkin DE, Ager AA, Thompson MP, Finney MA, Lee DC, Quigley TM, McHugh CW, Riley KL, Gilbertson-Day JW (2011) A comparative risk assessment framework for wildland fire management: the 2010 Cohesive Strategy Science Report. USDA Forest Service, Rocky Mountain Research Station, General Technical Report RMRS-GTR-262. (Fort Collins, CO)

Cohen JD, Deeming JE (1985) The National Fire Danger Rating System: basic equations. USDA Forest Service, Pacific Southwest Forest and Range Experiment Station, General Technical Report PSW-82. (Berkeley, CA)

Collins BM, Omi PN, Chapman PL (2006) Regional relationships between climate and wildfire-burned area in the Interior West, USA. Canadian Journal of Forest Research 36, 699-709. doi:10.1139/X05-264

Dai A, Trenberth KE, Qian T (2004) A global dataset of Palmer Drought Severity Index for 1870-2002: relationship with soil moisture and effects of surface warming. Journal of Hydrometeorology $\mathbf{5}$, 1117-1130. doi:10.1175/JHM-386.1

Daly C, Neilson RP, Phillips DL (1994a) A statistical-topographic model for mapping climatological precipitation over mountainous terrain. Joumal of Applied Meteorology 33, 140-158. doi:10.1175/1520-0450 (1994)033<0140:ASTMFM>2.0.CO;2

Daly C, Neilson RP, Phillips DL (1994b) A statistical-topographic model for mapping climatological precipitation over mountainous terrain. Joumal of Applied Meteorology 33, 140-158. doi:10.1175/1520-0450 (1994)033<0140:ASTMFM >2.0.CO;2

Diaz HF, Swetnam TW The wildfires of 1910: climatology of an extreme early 20th century event and comparison with more recent extremes. Bulletin of the American Meteorological Society, in press. doi:10.1175/ BAMS-D-12-00150.1

Eidenshink JC, Schwind B, Brewer K, Zhu Z-L, Quayle B, Howard S (2007) A project for monitoring trends in burn severity. Fire Ecology 3 , 3-21. doi: 10.4996/FIREECOLOGY.0301003

Fernandes K, Baethgen W, Bernardes S, DeFries R, DeWitt DG, Goddard L, Lavado W, Dong E (2011) L, Padoch C, Pinedo-Vasquez M, Uriarte M (2011) North Tropical Atlantic influence on western Amazon fire season variability. Geophysical Research Letters 38, L12701. doi:10.1029/ 2011 GL047392

Finney MA, Grenfell IC, McHugh CW (2009) Modeling containment of large wildfires using generalized linear mixed-model analysis. Forest Science 55, 249-255.

Finney MA, Grenfell IC, McHugh CW, Seli RC, Trethewey D, Stratton $\mathrm{RD}$, Brittain S (2011a) A method for ensemble wildland fire simulation. Environmental Modeling and Assessment 16, 153-167. doi:10.1007/ S10666-010-9241-3

Finney MA, McHugh CW, Grenfell IC, Riley KL, Short KC (2011b) A simulation of probabilistic wildfire risk components for the continental United States. Stochastic Environmental Research and Risk Assessment 25, 973-1000. doi:10.1007/S00477-011-0462-Z

Fosberg MA (1971) Climatological influences on moisture characteristics of dead fuel: theoretical analysis. Forest Science 17, 64-72. 
Fosberg MA, Rothermel RC, Andrews PL (1981) Moisture content calculations for 1000-hour timelag fuels. Forest Science 27, 19-26.

Gedalof Z, Peterson DL, Mantua NJ (2005) Atmospheric, climatic, and ecological controls on extreme wildfire years in the Northwestern United States. Ecological Applications 15, 154-174. doi:10.1890/03-5116

Guttman NB (1998) Comparing the Palmer Drought Index and the Standardized Precipitation Index. Journal of the American Water Resources Association 34, 113-121. doi:10.1111/J.1752-1688.1998. TB05964.X

Guttman NB, Wallis JR, Hosking JRM (1992) Spatial comparability of the Palmer Drought Severity Index. Water Resources Bulletin 28, 11111119. doi:10.1111/J.1752-1688.1992.TB04022.X

Henry AJ (1931) The calendar year as a time unit in drought statistics. Monthly Weather Review 59, 150-153. doi:10.1175/1520-0493(1931) $59<150$ :TCYAAT $>2.0 . \mathrm{CO} ; 2$

Hessl AE, McKenzie D, Schellhaas R (2004) Drought and Pacific Decadal Oscillation linked to fire occurrence in the inland Pacific Northwest. Ecological Applications 14, 425-442. doi:10.1890/03-5019

Heyerdahl EK, Morgan P, Riser JP, II (2008a) Multi-season climate synchronized historical fires in dry forests (1650-1900), Northern Rockies, USA. Ecology 89, 705-716. doi:10.1890/06-2047.1

Heyerdahl EK, Morgan P, Riser JP, II (2008b) Multi-season synchronized historical fires in dry forests (1650-1900), Northern Rockies, USA. Ecology 89, 705-716. doi:10.1890/06-2047.1

Holden ZA, Crimmins MA, Cushman SA, Littell JS (2011) Empirical modeling of spatial and temporal variation in warm season nocturnal air temperatures in two North Idaho mountain ranges, USA. Agricultural and Forest Meteorology 151, 261-269. doi:10.1016/J.AGRFORMET. 2010.10 .006

Kangas RS, Brown TJ (2007) Characteristics of US drought and pluvials from a high-resolution spatial dataset. International Journal of Climatology 27, 1303-1325. doi:10.1002/JOC. 1473

Karl TR (1986) The sensitivity of the Palmer Drought Severity Index and Palmer's Z-Index to their calibration coefficients including potential evapotranspiration. Journal of Climate and Applied Meteorology 25, 77-86. doi: 10.1175/1520-0450(1986)025<0077:TSOTPD >2. $0 . \mathrm{CO} ; 2$

Lewis HT (1973) 'Patterns of Indian Burning in California: Ecology and Ethnohistory'. (Ballena Press: Ramona, CA)

Littell JS, McKenzie D, Peterson DL, Westerling AL (2009) Climate and wildfire area burned in western U.S. ecoprovinces, 1916-2003. Ecological Applications 19, 1003-1021. doi:10.1890/07-1183.1

Lloyd-Hughes B, Saunders MA (2002) A drought climatology for Europe. International Joumal of Climatology 22, 1571-1592. doi:10.1002/ JOC.846

McCabe G, Dettinger MD (1999) Decadal variations in the strength of ENSO teleconnections with precipitation in the Western United States. International Journal of Climatology 19, 1399-1410. doi:10.1002/ (SICI) 1097-0088(19991115)19:13<1399::AID-JOC457>3.0.CO;2-A

McKee TB, Doesken NJ, Kleist J (1993) The relationship of drought frequency and duration to time scales. In 'Preprints, 8th Conference on Applied Climatology', 17-22 January 1993, Anaheim, CA. pp. 179-184. (American Meteorological Society: Boston, MA)

Miller JD, Skimner CN, Safford HD, Knapp EE, Ramirez CM (2012) Trends and causes of severity, size, and number of fires in northwestern California, USA. Ecological Applications 22, 184-203. doi:10.1890/102108.1

Morgan P, Heyerdahl EK, Gibson CE (2008) Multi-season climate synchronized forest fires throughout the 20th century, Northern Rockies, USA. Ecology 89, 717-728. doi:10.1890/06-2049.1

Omernik JM (1987) Ecoregions of the conterminous United States. Annals of the Association of American Geographers. Association of American Geographers 77, 118-125. doi:10.1111/J.1467-8306.1987.TB00149.X
Palmer WC (1965) Meteorological drought. US Department of Commerce, Research Paper number 45. (Washington, DC)

Preisler H, Westerling AL (2007) Statistical models for forecasting monthly large wildfire events in western United States. Journal of Applied Meteorology and Climatology 46, 1020-1030. doi:10.1175/ JAM2513.1

Preisler H, Burgan RE, Eidenshink JC, Klaver JM, Klaver RW (2009) Forecasting distributions of large federal-lands fires utilizing satellite and gridded weather information. International Journal of Wildland Fire 18, 508-516. doi:10.1071/WF08032

Ropelewski CF, Halpert MS (1986) North American precipitation and temperature patterns associated with the El Nino/Southern Oscillation (ENSO). Monthly Weather Review 114, 2352-2362. doi:10.1175/15200493(1986) $114<2352:$ NAPATP $>2.0 . \mathrm{CO} ; 2$

Rothermel RC (1972) A mathematical model for predicting fire spread in wildland fuels. USDA Forest Service, Intermountain Forest and Range Experiment Station, Research Paper INT-115. (Ogden, UT)

Schlobohm P, Brain J (2002) Gaining an understanding of the National Fire Danger Rating System. National Wildfire Coordinating Group, PMS 932, NFES 2665. Available at http:/www.nwcg.gov/var/products/gainingan-understanding-of-the-national-fire/at_download/file [Verified 28 June 2013]

Schmidt KM, Menakis JP, Hardy CC, Hann WJ, Bunnell DL (2002) Development of coarse-scale spatial data for wildland fire and fuel management. USDA Forest Service, Rocky Mountain Research Station, General Technical Report GTR-RMRS-87. (Fort Collins, CO)

Scott JH, Burgan RE (2005) Standard fire behavior fuel models: a comprehensive set for use with Rothermel's surface fire spread model. USDA Forest Service General Technical Report RMRS-GTR-153. (Fort Collins, $\mathrm{CO}$ )

Sellers WD (1965) 'Physical Climatology.' (University of Chicago Press: Chicago, IL)

Sheffield J, Wood EF, Roderick ML (2012) Little change in global drought over the past 60 years. Nature 491. doi:10.1038/NATURE11575

Strauss D, Bednar L, Mees R (1989) Do one percent of forest fires cause ninety-nine percent of the damage? Forest Science 35, 319-328.

Swetnam TW, Betancourt JL (1998) Mesoscale disturbance and ecological response to decadal climate variability in the American Southwest. Journal of Climate 11, 3128-3147. doi:10.1175/1520-0442(1998) $011<3128$ :MDAERT $>2.0 . \mathrm{CO} ; 2$

Thornthwaite CW (1948) An approach toward a rational classification of climate. Geographical Review 38, 55-94. doi:10.2307/210739

Thornthwaite CW (1953) Topoclimatology. In 'Proceedings of Toronto Meteorological Conference', 9-15 September 1953, Toronto, ON. pp. 227-232. (American Meteorological Society: Boston, MA; and Royal Meteorological Society: London)

Thornton PE, Thornton MM, Mayer BW, Wilhelmi N, Wei Y, Cook RB (2012) Daily surface weather on a $1 \mathrm{~km}$ grid for North America. Oak Ridge National Laboratory Distributed Active Archive Center. (Oak Ridge, TN) Available at http:/daymet.ornl.gov/ [Verified 4 May 2013]

Trouet V, Taylor AH, Carleton AM, Skinner CN (2009) Interannual variations in fire weather, fire extent, and synoptic-scale circulation patterns in northern California and Oregon. Theoretical and Applied Climatology 95, 349-360. doi:10.1007/S00704-008-0012-X

Van Wagner CE (1977) Conditions for the start and spread of crown fire. Canadian Journal of Forest Research 7, 23-34. doi:10.1139/X77-004

Westerling AL, Gershunov A, Cayan DR, Barnett TP (2002) Long lead statistical forecasting of area burned in western US wildfires by ecosystem province. International Journal of Wildland Fire 11, 257-266. doi: $10.1071 /$ WF02009

Westerling AL, Gershunov A, Brown TJ, Cayan DR, Dettinger MD (2003) Climate and wildfire in the western United States. American Meteorological Society 84, 595-604. doi:10.1175/BAMS-84-5-595 